\title{
IMPACT OF COVID-19 PANDEMIC DRASTICALLY ON THE ECONOMY OF PAKISTAN- DEEP INSIGHTS FOR POLICYMAKERS
}

\section{Safdar Hussain ${ }^{1}$, Abdul Saboor ${ }^{2}$, Shahzada M. Naeem Nawaz ${ }^{3}$, Zubair Khalid Saleemi ${ }^{4}$, Majid Ali ${ }^{*}$}

1,2,5* Department of Economics, Pir Mehr Ali Shah, Arid Agriculture University Rawalpindi, 46000, Pakistan;

${ }^{3}$ Research Fellow, Punjab Economic Research Institute (PERI), Pakistan; ${ }^{4}$ Associate Research Fellow, Punjab Economic Research Institute (PERI), Pakistan.

Email: ${ }^{1}$ ranasafdar@uaar.edu.pk, ${ }^{2}$ drabdul.saboor@uaar.edu.pk, ${ }^{3}$ drsmnawaz@peri.punjab.gov.pk,

${ }^{4}$ zksaleemi@gmail.com, ${ }^{5 *}$ majidali@uaar.edu.pk

Article History: Received on $10^{\text {th }}$ February 2021, Revised on $22^{\text {nd }}$ March 2021, Published on $24^{\text {th }}$ March 2021

\section{Abstract}

Purpose of the study: This article aims to examine the economic consequences of the unprecedented crisis of COVID19 across Pakistan's sectors. To date, the second phase of COVID-19 is underway, and the economic losses of the industries and the recovery plan are still underdeveloped.

Methodology: This study is qualitative based. Mix method and desk review approaches are used to analyse the impact of covid-19 on the different sectors of Pakistan

Main Findings: The review revealed that the pandemic had a range of negative impacts on domestic, foreign trade, health care, education, and tourism, but had a positive effect on the environment and the agriculture sector.

Applications of this study: This study can be effective for the researcher to an immediate need to study each sector's economic insights further to improve crisis management policy.

Novelty/Originality of this study: this research contributes to the covid-19 pandemic in the different sectors of Pakistan. It also offers insights into how policymakers should build policies.

Keywords: COIVD-19, Economy of Pakistan, International Trade, Mixed-method Approach, Policymakers.

\section{INTRODUCTION}

The COVID-19 caused an unprecedented impact on the economy, domestic and international trade, healthcare, industries, agriculture, tourism, and the education system. It became an utmost challenge for society to handle this global crisis (Shafi et al. 2020, He et al., 2020). This spread affected life walks, such as economic, human, religious, political, social, and financial structures of the entire world (Martin et al. 2020). The most affected countries are China, Italy, the USA, France, UK, Germany, India, Iran, and many others. Among them, some countries managed to control it well like; China, New Zealand and Pakistan, These countries have also been affected by it very badly in the first wave but for some time they managed to control it but now again there has been a second wave of the virus which is severe than first wave (Lin et al. 2020, Shafi et al. 2020).

The economic losses in the global perspective, report of the Asian Development Bank (ADP) published in May 2020, the global economy would bear the cost of $\$ 5.8$ to $\$ 8.8$ trillion due to COVID-19. According to the reports, the economy of the UK shrank by $20.4 \%$ in the second quarter of 2020 (Ibarra-Vega 2020). The economy of Australia shrank 7\% and fell into a deep recession in the second quarter of 2020. The GDP of Japan shrank by $27.8 \%$ in the second quarter of 2020 and continues to shrink. It is the worst decline in history after World War II. South Korea also got into a recession in 17 years in August 2020. Latin American economies are expected to contract by 9.4\% in FY20 (Fernandes 2020).

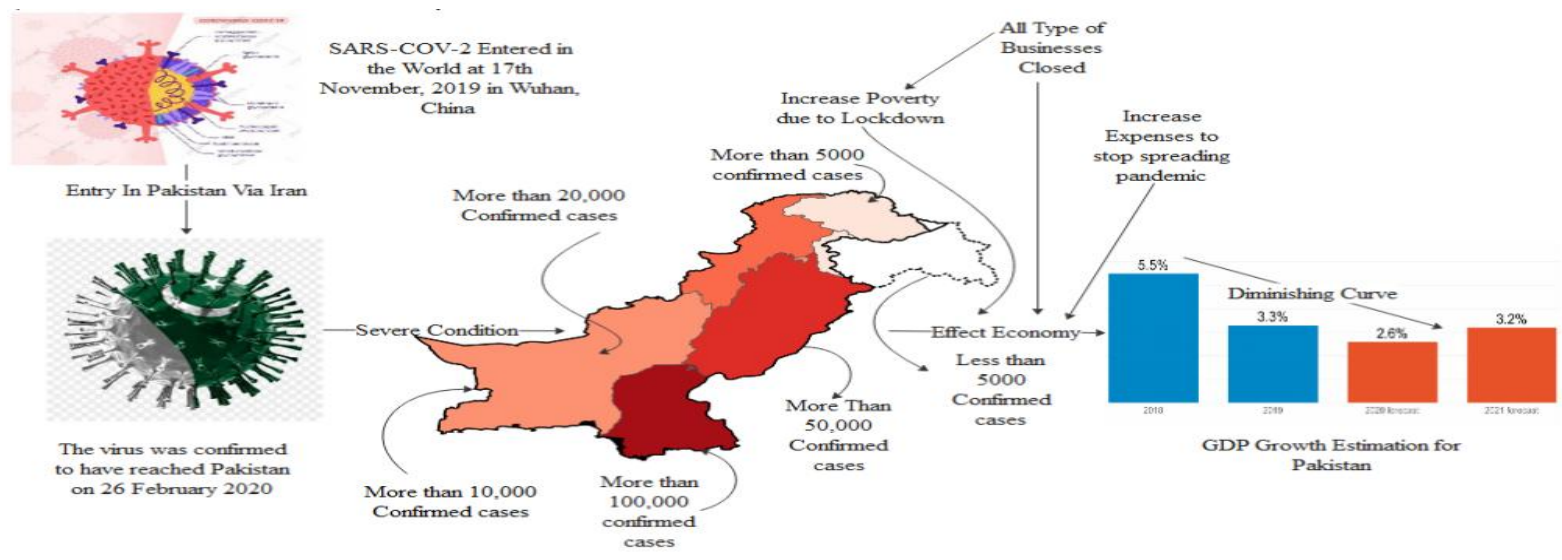

Figure 1: GDP growth in Pakistan and COVID-19 pandemic

Source: Azam et al. (2020) 
In the context of Pakistan, since the first case of COVID-19 was reported in Karachi, this pandemic disrupted all felids, such as industrial, agricultural, healthcare, domestic and international trade, financial market, and tourism (Sahin et al. 2020). These sectors are crucial for the economy as they contribute $40 \%$ to the GDP with over $40 \%$ to export earnings (Shafi et al. 2020). These business spread all over the country and represent a significant indicator for Pakistan's economy. Besides, this pandemic has brought the unemployment challenge as many Pakistani have lost their jobs in foreign countries and remittances sharply decreased. A recent review by Azam et al. (2020) revealed that if the retail and food sector fully open in COVID-19, the GDP could fall to $2 \%$ because the government was expecting 3.3-3.4 percent GDP growth before the crisis but now the estimations have been cut to 2-2.8 percent (see figure-1), the deficit will hit 9\% because of increase in expenditure demand and fall in taxes and non-tax revenues (Kushel et al. 2006).

The challenge brings uncertainty and hidden corona rises in different labor sectors were reported in Rabo Research (Figure-2). It has led the lives of people into crisis as most of the people lost their source of income. It has not done any discrimination among people and countries as it has also affected the rich and developed countries the same as poor and developing ones (Seetharaman 2020). Besides, it has also affected global economic activities due to the reduction in GDP growth and increases in fiscal, monetary, trade, and current account deficit of most of the countries which have made economies more sluggish as it has affected both private and public sectors (Barnes 2020). It has already been a year since the first case of COVID-19 was detected but the world is still helpless to get free of this pandemic (Pan et al. 2020). Nevertheless, it is quite unclear that businesses around the world are experiencing the impact of the COVID-19 pandemic on their business. We argue in this study that major victims of the COVID-19 pandemic are the service and manufacturing sectors of Pakistan.

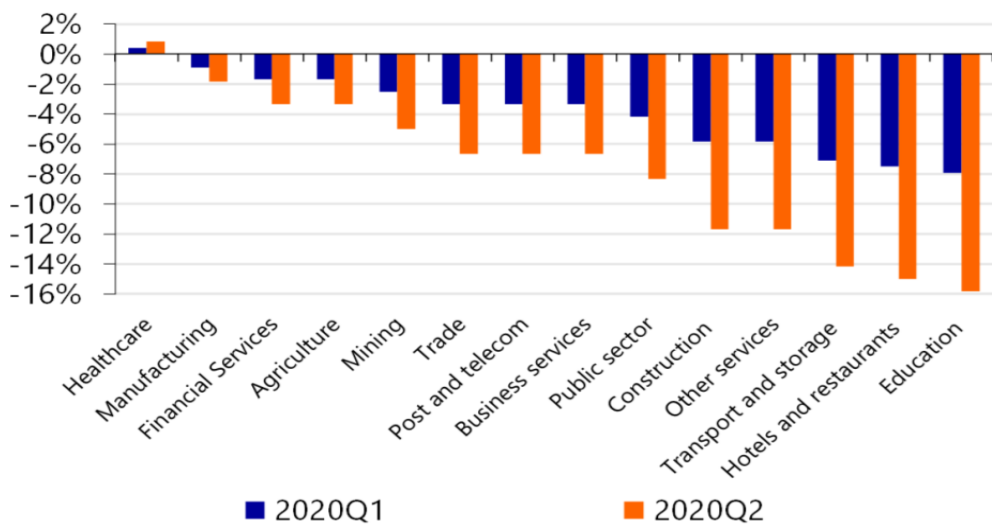

Figure 2: Hidden corona crises sector wise

This review article aims to examine the impact of the COVID-19 pandemic on Pakistan in different sectors, such as manufacturing, agriculture, health care, education, and tourism. Also, this article also provides deep insights from an economic perspective to policymakers for crisis management in different fields, such as domestic and foreign trade, the financial and business markets, the labour force, and the environment. This article is an initial attempt to explore the details from every sector that has triggered an ongoing pandemic.

\section{METHODOLOGY}

\section{Theoretical Framework}

This analysis is focusing on the qualitative and quantitative data discretely. The mixed-method study is composed of three phases with a sequential explanatory design. The first phase is a qualitative study to explore the industrial and agriculture sector production and growth, health, and education difficulties during the COVID-19 pandemic. Through purposeful sampling, the subjects will be selected in this stage and an extensive interview used for the collection of data. Finally, for data analysis, the conventional content analysis approach is used. The second phase is quantitative and is used to evaluate the association of domestic and international trade and labor force factors in a cross-sectional approach. Multi-phase cluster sampling is used for the collection of health data in different areas of Pakistan. The third phase will focus on the development, using the qualitative and quantitative results from the previous phases, of health care guidelines and strategies, a literature review, and nominal group techniques between experts.

The desk review approach is used for taking data. Internal and external both approaches are used. An internal desk review is organised within an organization but the external desk approach is arranged through online on the internet, direct to customers, and the government websites. The desktop evaluation is an important element of this evaluation: the team gains an understanding of the country context, public health priorities, and health trends by collecting, organising, and synthesising available information, and identifies gaps that must be addressed during in-country work. Desk reviews include literature scan, secondary data analysis, and the creation of a reference list to organise all the documents and allow them to be easily accessible for all team members. 


\section{IMPACT OF COVID-19 ON DIFFERENT SECTORS}

\section{Industrial Sector}

The industrial sector is one of the most affected sectors by COVID-19 all over the world (Shen et al. 2020). Industries have led to a great loss as the lockdown was imposed. Unfortunately, industries had no option other than to close for a temporary period (Ibarra-Vega 2020), and the result was that there was no production and growth (He et al. 2020). Mostly the developed nations are more affected in terms of the industrial sector as their economy depends on industrial production and most of their revenue generation is from the industries (Ketchen and Craighead 2020). In the industrial sector, the most affected industries are automobile, chemical, food, electronics, pharmaceutical, machinery, medical equipment industries. Likewise, it has also affected micro, small, and medium-sized industries very badly (Shafi et al. 2020).

The electronics industry is on the top negatively affected as China accounts for almost $85 \%$ of the total value of smartphone raw material and $75 \%$ for the television. It also imports other components like LED and mobile displays, panels, capacitors, circuits, memory, and many other electronic items all over the world (Seetharaman 2020). When COVID-19 hit China, most of its industries were shut down which resulted in a shortage of those components in the world market as there was no production (Guan et al. 2020). Due to this, China had increased its prices by 2-3\% for some time. In the region of Asia-Pacific, China is the most affected country as it is an industrial hub and almost all the top industries have their units in China (Guan et al. 2020).

On the other hand, medical equipment and machinery manufacturers also get affected positively as we know that in the beginning there was a massive demand for testing kits, masks, medical suits, and machinery and there is trade going on these among countries to control the pandemic (Rusinko 2020, Coombs 2020). They are still now among gainers as COVID-19 is hyping again. Mostly the developing countries are trading on these due to a lack of medical facilities to accommodate the affected people. Pharmaceutical countries got affected positively as well as negatively. Medicines for the COVID-19 patients were traded more than ever but no other medicines due to lockdown leading to the shortage (Shafi et al. 2020).

In the context of OPEC, the oil demand has fallen dramatically, leading to a drop in oil prices at the outset (Malliet et al. 2020, Ponkratov et al. 2020). This has contributed to a decrease in the trading of oil by OPEC around the world, as foreign trade has been limited, and also due to low demand. But it has had a dramatic effect on the manufacturing sector as they use oil as raw material and for shipping so that they have been unable to produce enough for domestic demand. This impact on OPEC may be a positive sign, as it somehow contributes to the preservation of oil supply, which has risen massively in the last few years, reducing the projected availability of natural resources for the future (Malliet et al. 2020).

\section{Agricultural Sector}

The impact of COVID-19 on the agricultural sector is both positive and negative. Domestically, the agricultural sector has had a positive impact for a short period, as demand for food increased enormously due to panic-stricken purchases. But after some time, the impact began to be negative, as there was a shortage of supplies due to panic buying and shutting down industries (Pu and Zhong 2020, Shen et al. 2020). The negative impact has been shown as restaurants, hotels, food industries have been shut down due to COVID-19 (Martin et al. 2020). The agricultural sector has been negatively affected internationally as trade has been restricted, agricultural raw materials have been reduced and no production has been produced. All of these have prevented agricultural goods from entering the market at the national and international levels (Pu and Zhong 2020).

Developed nations seem to be more at a loss compared to developing and least developed nations, as developing nations are not that technology-based or industrialised as most of them have expertise in agriculture (Sein 2020), and we know that food demand has been rising all over the world at the beginning. Whereas developed nations are mostly technologybased, and there has been a massive decline in demand for their commodities. Technology-based nations, therefore, suffer more than agricultural-based nations (

\section{Domestic and International Trade}

Economically, the most affected part is the domestic and international trade and also all the factors related to it. International trade in almost every country has got affected (Lehdonvirta et al. 2018). Due to this pandemic, transportation has been restricted and many business operations have been suspended increasing the trade deficit of many nations. Trade has faced too many problems because it has not affected only a few nations but the whole world affecting the import and exports of every nation (Malliet et al. 2020). As there was no trade occurring between countries, there has been a great decline in the trade market. The trade market has faced a huge contraction in fiscal year 20 (Pan et al. 2020). The graph presented in Figure 3, shows the World services trade activity index from 2007Q1 to 2020Q2 (WTO 2020). 


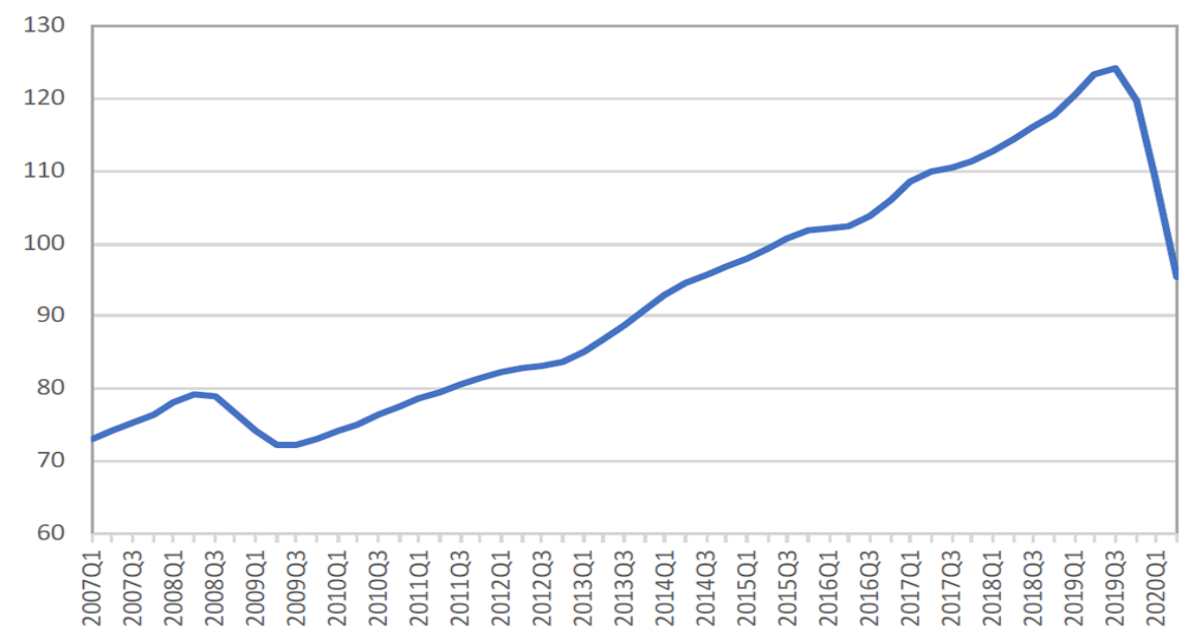

Figure 3: World service trade activity index

Globalization got targeted by the COVID-19 as no country was in a situation to do trade. The borders of almost every country have been sealed creating a trade barrier leading to lower the comparative advantage for most countries on commodities. No country was in a condition to enjoy a comparative advantage as neither they are in a condition to produce more and got into that competition as trade has been restricted (Pan et al. 2020).

Trade restrictions affect the distribution of income in a way that when a trade occurs, it increases the wage rate and decreases the interest rate in labor abundant countries and decreases the wage rate and increasing the interest rate in capital abundant countries creating a balance between them ( $\mathrm{He}$ et al. 2020). Keeping this concept in mind, we can examine it regarding the current situation that without trade there is a disruption creating in the economy as the wage rate has decreased and the interest rate has increased.

There has been a global lockdown which led to increasing inflation all over the world as prices of raw materials and taxes on imports are increased resulting inflation rate boost of about $11.12 \%$ in FY20. As a result, there has been a reduction in trade and politico-economic activities (Ibarra-Vega 2020). However, in Pakistan, Prime Minister announced smart lockdown (refer Figure), which mean that are only infected area will be closed and the working areas will have to follow proper SOPs (Azam et al. 2020).

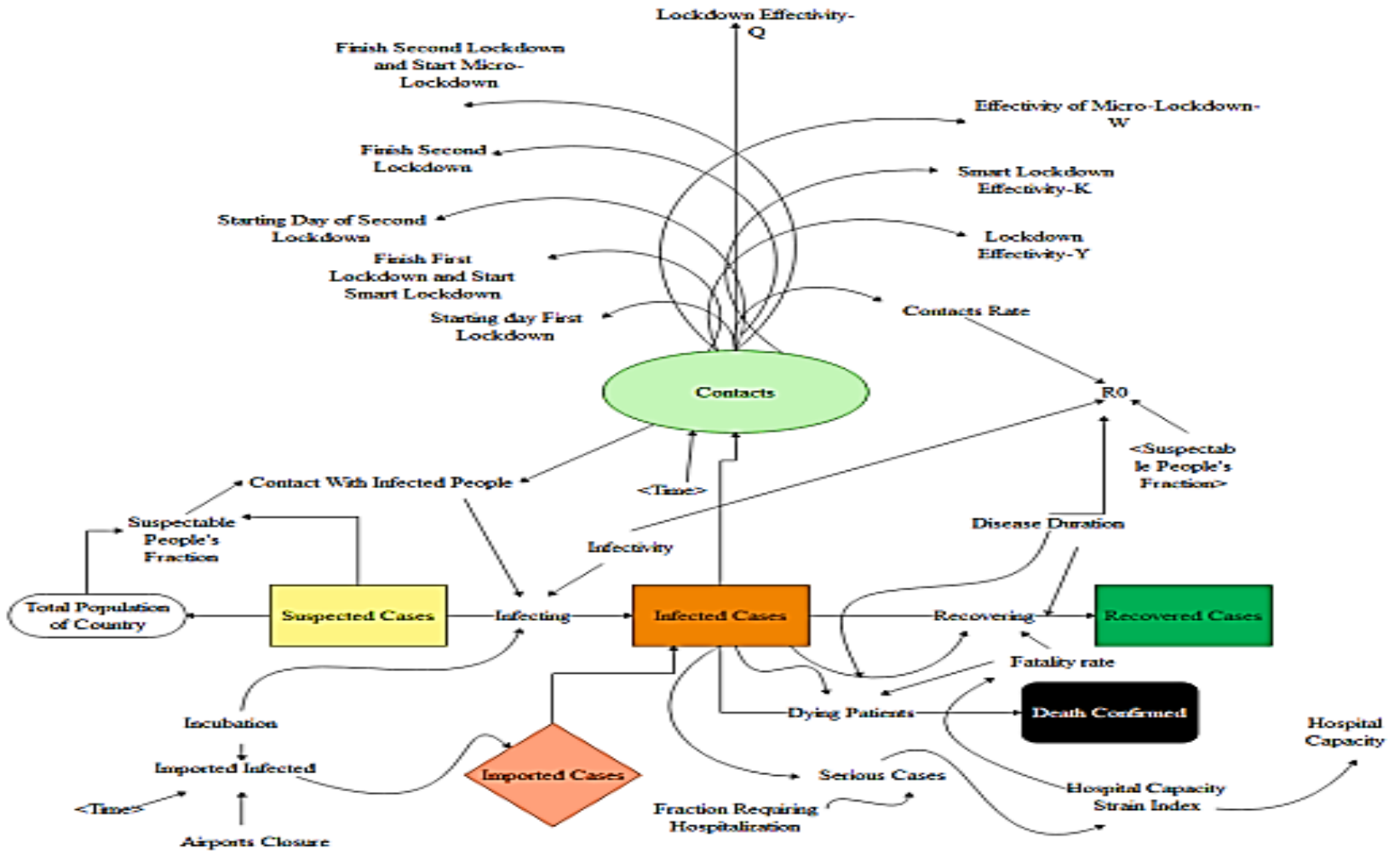

Figure 4: Smart lockdown of Pakistan

Source: Azam et al. (2020) 


\section{Financial Market and Businesses}

COVID-19 has impacted the financial market to the worst level as the stock markets all over the world faced huge losses in points of the stock index (Pan et al. 2020). It is also plunging stock prices and bond yield leading towards the crash of the stock market and crisis. There has been a decline in economic growth, investments, exports, imports, business operation, and many other things which has almost crashed the world economy (Fernandes 2020). The unemployment, poverty, and inequality rate has been increased worldwide which has led to an impact on the global economy negatively. COVID-19 is leaving a long-term impact in terms of a decrease in investment, erosion of human capital due to unemployment, and restriction on globalization and supply linkages. As a result, economies are going into deep recessions (Martin et al. 2020).

Stock markets are severely damaged due to COVID-19 as investors are removing their money due to fear of loss in a pandemic situation. Almost $\$ 83$ billion money has been removed by the investors from the multiple businesses working in emerging markets and more are expected (Azam et al. 2020). Due to this worse economic situation, the economic structure has been badly disturbed and there are no more investments as a result of which the businesses are shutting down. The currencies of different countries also lead to devaluation resulting in lowering the economic growth and declining of the foreign market.

\section{Labor Force}

The Labour force has been directly affected by COVID-19 because millions of people are left unemployed (Martin et al. 2020). It has directly affected the wage rate as there is a reduction in demand and supply directly affecting the factor prices. It is expected that the labor force will continue to lose their jobs all over the world as the business conditions are not favourable which is leading them to shut down because they will be unable to pay the wages to their employees. Also, transportation has been restricted and producers are unable to supply which is one of the reasons for the negative impact of COVID-19 on the labor force (Coombs 2020).

This pandemic has caused devastating economic and social disruption (Nicola et al. 2020). There are tens of millions of people that are at risk of falling into extreme poverty. The undernourished people are expected to increase by up to 132 million at the end of FY20 which currently is estimated at almost 690 million (WTO 2020). Globally, millions of workers are facing a high level of malnutrition, poor health, and are suffering from a lack of social protection. Due to income losses, an increase in child labor, predatory loans, and the selling of assets is expected. The Labour force of all the countries is affected but it has created the worst affected on the least-developed countries in which people were already fighting for their survival and now they are in their worst of the worst crisis (Rao et al. 2020). This population includes mostly farmers and indigenous people. It is most likely to increase poverty and inequalities worldwide making strategic development goals (SDGs) even more difficult but urgent to achieved by countries (Nicola et al. 2020).

According to the IMF World Economic Outlook, October 2020, and World Bank Povcal data, the change in poverty due to COVID-19 has occurred in this pattern. This data has been extracted from the analysis of 183 countries (See Table 1)

Table 1: Poverty statistics year wise

\begin{tabular}{llll}
\hline Poverty & $\mathbf{2 0 1 9}$ & $\mathbf{2 0 2 0}$ & $\mathbf{2 0 2 1}$ \\
\hline Pre-COVID & $650,4333,712$ & $621,931,609$ & $598,347,067$ \\
& $(8.4 \%)$ & $(8.0 \%)$ & $(7.6 \%)$ \\
\hline October 2020 & $646,806,659$ & $766,032,180$ & $726,524,822$ \\
& $(8.4 \%)$ & $(9.9 \%)$ & $(9.3 \%)$ \\
\hline
\end{tabular}

Global economies struggling with rising unemployment and their yearly change in unemployment rate 2019-2020 (Refer Figure 5).

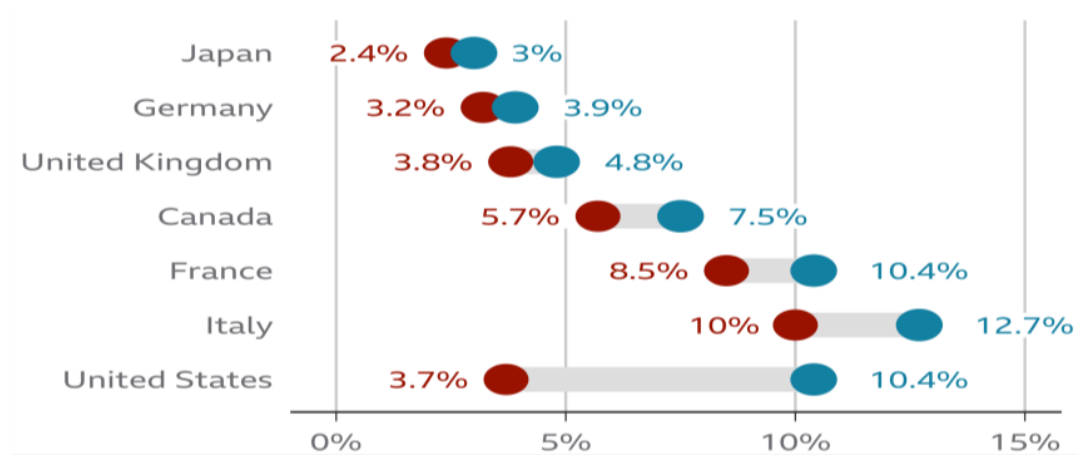

Figure 5: Unemployment Graph

Source:(Narula 2020) 


\section{Healthcare Sector}

The most important and front-line sector in this current pandemic situation is the health sector which handles the COVID-19 crises (Rao et al. 2020). The health sector has been facing many difficulties due to the huge spread of COVID-19. The health sector all over the world fell short of medical facilities. Thousands of people lost their lives and millions got affected and still getting affected. The prices of medicines increased to a great extent due to huge demand (Barnes 2020).

COVID-19 has harmed the global economy more than the time of World War-II. It had cost millions of human lives that are immeasurable (Coombs 2020). All countries should try to work together with cooperation and coordination to limit and recover the economic damages and to protect human beings. This crisis has converged public health, employment, food security, and social protection (Rusinko 2020). Most of the countries were already dealing with humanitarian crises and now when they got exposed to the effects of COVID-19, the situation has worsened even more. On the other hand, COVID-19 brings opportunities for healthcare producers in Pakistan to manufacture personal protective equipment (PPE), such as masks, gloves, gowns, and export at the international level (Chughtai and Khan 2020).

\section{Educational Sector}

The education sector has been impacted very badly by the COVID-19 pandemic (Cao et al. 2020). Governments all over the world have closed educational institutions temporarily to control the spread of the COVID-19 (Dwivedi et al. 2020). These closures have impacted the education of hundreds of millions of students as they have lost their time to learn. Exams were canceled which affected the grades of students badly as they got passed on predicted grades (Cao et al. 2020).

Online classes are conducted all over the world but they are not the best alternative to physical education (PanovskaGriffiths et al. 2020). Students who went to other countries for the sake of education faced so many problems as universities and airspace were closed and they got stuck there. They were not able to get to their homes (PanovskaGriffiths et al. 2020).

\section{Environment}

There has been some positive impact on the environment of COVID-19 (Malliet et al. 2020). Due to this global disruption, which has restricted trade and slowed down social and economic activities, the air and water quality has been improved in different parts of the world. It has decreased the level of carbon emissions which is damaging the ozone layer. It has also led to a decline in the GHG concentration (Ibarra-Vega 2020).

Many birds and animals have been seen in their natural habitat after so long as they migrated in the past because of pollution caused by humans and the population settled near their habitat. Many expected extinct animals have also been seen due to the improvement in the environment, no transportation traffic, and no human population rushing around (Malliet et al. 2020).

In China, the measures taken to control COVID-19 have resulted in a $25 \%$ decline in carbon emissions and a $50 \%$ decline in nitrogen oxide emissions. According to Earth Systems scientists, it is estimated that due to these at least 77,000 lives got saved in over two months (Pan et al. 2020).

But all these positive impacts are for a shorter time because as soon as the global economic activity gets back to normal, the environmental condition will again continue to degrade. So declining GHG concentration for a short period is not a sustainable solution to save the environment.

\section{Tourism}

Tourism has been drastically impacted by COVID-19 (Couto et al. 2020). The airspace of every country was closed and there was a lockdown situation as well which affected domestic and international travelling. Tourism-centric countries were amongst the worst as their economies lie on the revenue that comes from tourism. Other countries also get affected as the airlines and other transportation were closed, so there had been no revenue generation for the economies through that source. Due to the closing of airspace and transportation, the business operation and meetings were suspended leading to the loss of multiple businesses and economies (Couto et al. 2020).

\section{CONCLUSION}

This review article aims to explore the positive and negative effects of the COVID-19 pandemic on the economy in different sectors of Pakistan. Concluded, it is revealed that such kind of unprecedented crises doesn't give an option for a quick recovery to overcome the situation. The literature testifies that scientists and scholars and the government have always come up with an effective solution for crisis management. Fortunately, the Government of Pakistan exercised a rescue approach by imposing the smart lockdown in the infected area and gained quite better results with compare to the rest of the world; however, the damages due to this pandemic in all sectors has not fully controlled due to fewer resources. In healthcare, the Government unable to provide personal protective equipment (PPE), such as masks, gloves sanitizers, and gowns to healthcare staff around the country timely. 


\section{LIMITATION AND STUDY FORWARD}

Faculty and students said they could not do practicals through online learning methods. Only knowledge components can be taught and assessed. As teachers were not able to assess their understanding during online lectures because they lacked immediate feedback. The students have also shown that the intensive nature of online learning is limited in terms of attention and resources. Some teachers also said that students misbehaved and tried to access online resources during evaluations during the online study.

Instructors and learners both proposed the development of sustained professorships. They suggested that the cognitive stress be reduced and that interactivities be increased during online education. These suggested ways to start Case-Based Learning online in clinical years. But some also thought that revision classes should be conducted in conjunction with psychomotor hands after the COVID-19 pandemic is monitored. To improve quality, they proposed the purchase of high-quality software and other protocols to detect fraud and plagiarism.

\section{ACKNOWLEDGEMENT}

I am very sincerely thankful to all my co-authors Abdul Saboor, Shahzada M. Naeem Nawaz, and Shahzad Mushtaq who fully contribute to this pandemic research. I hope this research paper will helpful for every future researcher who wants to do work on COVID-19.

\section{AUTHORS CONTRIBUTION}

The authors of this research paper, Safdar Hussain and Abdul Saboor conceived of the presented idea. Shahzada M. Naeem developed the theory and performed the computations. Shahzad Mushtaq verified the analytical methods. Safdad Hussain encouraged Shahzad Mushtaq to investigate the desk review and mixed approaches and data analysis and supervised the findings of this work. All authors discussed the results and contributed to the final manuscript.

\section{REFERENCES}

1. Azam, T., Mohsin, M., Naseem, S., Nilofar, M., Zia-UR-Rehman, M., Nelofer, S., Khan, S. and SongJiang, W. (2020). Economic Growth Vulnerability Amid the COVID-19 Epidemic: A Systematic Review of Different Sectors of Pakistan. Revista Argentina de Clínica Psicológica, 29(4), pp. 705.

2. Barnes, S.J. (2020). Information management research and practice in the post-COVID-19 world. International Journal of Information Management, 55, pp. 102175. https://doi.org/10.1016/j.ijinfomgt.2020.102175

3. Cao, W., Fang, Z., Hou, G., Han, M., Xu, X., Dong, J. and Zheng, J. (2020). The psychological impact of the COVID-19 epidemic on college students in China. Psychiatry Research, 287, pp. 112934. https://doi.org/10.1016/j.psychres.2020.112934

4. Chughtai, A.A. and Khan, W. (2020). Use of personal protective equipment to protect against respiratory infections in Pakistan: A systematic review. Journal of Infection and Public Health, 13(3), pp. 385-90. https://doi.org/10.1016/j.jiph.2020.02.032

5. Coombs, C. (2020). Will COVID-19 be the tipping point for the Intelligent Automation of work? A review of the debate and implications for research. International Journal of Information Management, 55, pp. 102182. https://doi.org/10.1016/j.ijinfomgt.2020.102182

6. Couto, G., Castanho, R.A., Pimentel, P., Carvalho, C., Sousa, Á. and Santos, C. (2020). The Impacts of COVID-19 Crisis over the Tourism Expectations of the Azores Archipelago Residents. Sustainability, 12(18), pp. 7612. https://doi.org/10.3390/su12187612

7. Dwivedi, Y.K., Hughes, D.L., Coombs, C., Constantiou, I., Duan, Y., Edwards, J.S., Gupta, B., Lal, B., Misra, S., Prashant, P., Raman, R., Rana, N.P., Sharma, S.K. and Upadhyay, N. (2020). Impact of COVID-19 pandemic on information management research and practice: Transforming education, work and life. International Journal of Information Management, 55, pp. 102211. https://doi.org/10.1016/j. ijinfomgt.2020.102211

8. Fernandes, N. (2020). Economic effects of coronavirus outbreak (COVID-19) on the world economy. Available at SSRN 3557504. https://doi.org/10.2139/ssrn.3557504

9. Guan, W.-j., Liang, W.-h., Zhao, Y., Liang, H.-r., Chen, Z.-s., Li, Y.-m., Liu, X.-q., Chen, R.-c., Tang, C.-1. and Wang, T. (2020). Comorbidity and its impact on 1590 patients with Covid-19 in China: A Nationwide Analysis. European Respiratory Journal, 55(5). https://doi.org/10.1183/13993003.00547-2020

10. He, W., Zhang, J. and Li, W. (2020). Information Technology Solutions, Challenges, and Suggestions for Tackling the COVID-19 Pandemic. International Journal of Information Management, pp. 102287. https://doi.org/10.1016/j.ijinfomgt.2020.102287

11. Ibarra-Vega, D. (2020). Lockdown, one, two, none, or smart. Modeling containing covid-19 infection. A conceptual model. Science of The Total Environment, 730, pp. 138917. https://doi.org/10.1016/j.scitotenv.2020.138917

12. Ketchen, D.J. and Craighead, C.W. (2020). Research at the Intersection of Entrepreneurship, Supply Chain Management, and Strategic Management: Opportunities Highlighted by COVID-19. Journal of Management, 46(8), pp. 1330-41. https://doi.org/10.1177/0149206320945028 
13. Kushel, M.B., Gupta, R., Gee, L. and Haas, J.S. (2006). Housing instability and food insecurity as barriers to health care among low-income Americans. Journal of General Internal Medicine, 21(1), pp. 71-77. https://doi.org/10.1111/j.1525-1497.2005.00278.x

14. Lehdonvirta, V., Kässi, O., Hjorth, I., Barnard, H. and Graham, M. (2018). The Global Platform Economy: A New Offshoring Institution Enabling Emerging-Economy Microproviders. Journal of Management, 45(2), pp. 567-99. https://doi.org/10.31235/osf.io/jt4z7

15. Lin, Q., Zhao, S., Gao, D., Lou, Y., Yang, S., Musa, S.S., Wang, M.H., Cai, Y., Wang, W., Yang, L. and He, D. (2020). A conceptual model for the coronavirus disease 2019 (COVID-19) outbreak in Wuhan, China with individual reaction and governmental action. International Journal of Infectious Diseases, 93, pp. 211-16. https://doi.org/10.1016/j.ijid.2020.02.058

16. Malliet, P., Reynès, F., Landa, G., Hamdi-Cherif, M. and Saussay, A. (2020). Assessing Short-Term and LongTerm Economic and Environmental Effects of the COVID-19 Crisis in France. Environmental and Resource Economics, 76(4), pp. 867-83. https://doi.org/10.1007/s10640-020-00488-Z

17. Martin, A., Markhvida, M., Hallegatte, S. and Walsh, B. (2020). Socio-Economic Impacts of COVID-19 on Household Consumption and Poverty. Economics of Disasters and Climate Change, 4(3), pp. 453-79. https://doi.org/10.1007/s41885-020-00070-3

18. Narula, R. (2020). Policy opportunities and challenges from the COVID-19 pandemic for economies with large informal sectors. Journal of International Business Policy, 3(3), pp. 302-10. https://doi.org/10.1057/s42214$\underline{020-00059-5}$

19. Nicola, M., Alsafi, Z., Sohrabi, C., Kerwan, A., Al-Jabir, A., Iosifidis, C., Agha, M. and Agha, R. (2020).The socio-economic implications of the coronavirus pandemic (COVID-19): A review. International Journal of Surgery, 78, pp. 185-93. https://doi.org/10.1016/j.ijsu.2020.04.018

20. Pan, S.L., Cui, M. and Qian, J. (2020). Information resource orchestration during the COVID-19 pandemic: A study of community lockdowns in China. International Journal of Information Management, 54, pp. 102143. https://doi.org/10.1016/j.ijinfomgt.2020.102143

21. Panovska-Griffiths, J., Kerr, C.C., Stuart, R.M., Mistry, D., Klein, D.J., Viner, R.M. and Bonell, C. (2020). Determining the optimal strategy for reopening schools, the impact of test and trace interventions, and the risk of occurrence of a second COVID-19 epidemic wave in the UK: a modelling study. The Lancet Child \& Adolescent Health, 4(11), pp. 817-27. https://doi.org/10.1016/S2352-4642(20)30250-9

22. Ponkratov, V., Kuznetsov, N., Bashkirova, N., Volkova, M., Alimova, M., Ivleva, M., Vatutina, L. and Elyakova, I. (2020). Predictive Scenarios of the Russian Oil Industry; with a Discussion on Macro and Micro Dynamics of Open Innovation in the COVID 19 Pandemic. Journal of Open Innovation: Technology, Market, and Complexity, 6(3), pp. 85. https://doi.org/10.3390/joitmc6030085

23. $\mathrm{Pu}, \mathrm{M}$. and Zhong, Y. (2020). Rising concerns over agricultural production as COVID-19 spreads: Lessons from China. Global Food Security, 26, pp. 100409. https://doi.org/10.1016/j.gfs.2020.100409

24. Rao, H.R., Vemprala, N., Akello, P. and Valecha, R. (2020). Retweets of officials' alarming vs reassuring messages during the COVID-19 pandemic: Implications for crisis management. International Journal of Information Management, 55, pp. 102187. https://doi.org/10.1016/j.ijinfomgt.2020.102187

25. Rusinko, C. (2020). IT responses to Covid-19: rapid innovation and strategic resilience in healthcare. Information Systems Management, 37(4), pp. 332-38. https://doi.org/10.1080/10580530.2020.1820637

26. Sahin, A.R., Erdogan, A., Agaoglu, P.M., Dineri, Y., Cakirci, A.Y., Senel, M.E., Okyay, R.A. and Tasdogan, A.M. (2020). 2019 novel coronavirus (COVID-19) outbreak: a review of the current literature. EJMO, 4(1), pp. 1-7. https://doi.org/10.14744/ejmo.2020.12220

27. Seetharaman, P. (2020). Business models shifts: Impact of Covid-19. International Journal of Information Management, 54, pp. 102173. https://doi.org/10.1016/j.ijinfomgt.2020.102173

28. Sein, M.K. (2020). The serendipitous impact of COVID-19 pandemic: A rare opportunity for research and practice. International Journal of Information Management, 55, pp. 102164. https://doi.org/10.1016/j.ijinfomgt.2020.102164

29. Shafi, M., Liu, J. and Ren, W. (2020). Impact of COVID-19 pandemic on micro, small, and medium-sized Enterprises operating in Pakistan. Research in Globalization, 2, pp. 100018. https://doi.org/10.1016/j.resglo.2020.100018

30. Shen, H., Fu, M., Pan, H., Yu, Z. and Chen, Y. (2020). The Impact of the COVID-19 Pandemic on Firm Performance. Emerging Markets Finance and Trade, 56(10), pp. 2213-30. https://doi.org/10.1080/1540496X.2020.1785863

31. WTO. (2020). Trade shows signs of rebound from COVID-19, recovery still uncertain. World Trade Organization. 